\title{
Brecht e a "Teoria do rádio"
}

CELSO FREDERICO

"Não existe nenhuma possibilidade de evitar o poder da desconexão mediante a organização dos desconectados?”

A S REFLEXÕES pioneiras de Brecht sobre o rádio estão sintetizadas num conjunto de breves artigos sobre esse então novo meio de comunicação, escritos entre 1927 e 1932, no mesmo período das "peças didáticas". 1 Em ambas as intervenções encontram-se o apelo à participação, o incentivo para que o mundo do trabalho tome a palavra. Os conhecimentos teóricos do teatro épico, diz Brecht, podem e devem ser aplicados à radiodifusão.

O novo teatro e o novo meio de comunicação caminham juntos para realizar o imperativo de interatividade, deixando para trás o antigo conceito que via a cultura como uma forma que "já está constituída” e, portanto, "não carece de qualquer esforço criativo continuado".

O “esforço criador", tanto no teatro como na radiodifusão, não se contentava com o "aprimoramento" dessas entidades, de abastecê-las com bons produtos, mas visava à sua transformação radical. Vale aqui lembrar a famosa passagem de "Notas sobre Mahagonny", escritas em 1930:

a engrenagem é determinada pela ordem social; então não se acolhe bem senão o que contribui para a manutenção da ordem social. Uma inovação que não ameace a função social da engrenagem [...] pode por ela ser apreendida. Mas as que tornam iminente a mudança dessa função e procuram dar à engrenagem uma posição diferente na sociedade [...] é renegada por ela. A sociedade absorve por meio da engrenagem apenas o que necessita para sua perpetuação. (Brecht, 1967, p.56)

Brecht não tinha ilusões sobre a capacidade de cooptação e neutralização do sistema, e, como marxista, observou muito antes de Adorno o primado da produção sobre o consumo dos bens simbólicos ao afirmar que "é a engrenagem que elabora o produto para consumo".

As radicais e muito criativas teses brechtianas sobre o rádio e o teatro exprimem, como não poderia deixar de ser, o momento histórico vivido pelos intelectuais alemães, ainda marcado pelo entusiasmo provocado pela revolução russa de 1917 e pela certeza de que a revolução, abortada na Alemanha em 1919, em breve triunfaria.

A agitação política do período foi acompanhada de uma intensa fermentação cultural em que se discutiam o esgotamento das formas tradicionais de se fazer arte e a busca de novas formas de comunicação. Nesse sentido, os alemães reproduziram em boa parte o debate russo sobre o novo papel da arte na sociedade a ser construída. ${ }^{2}$ 


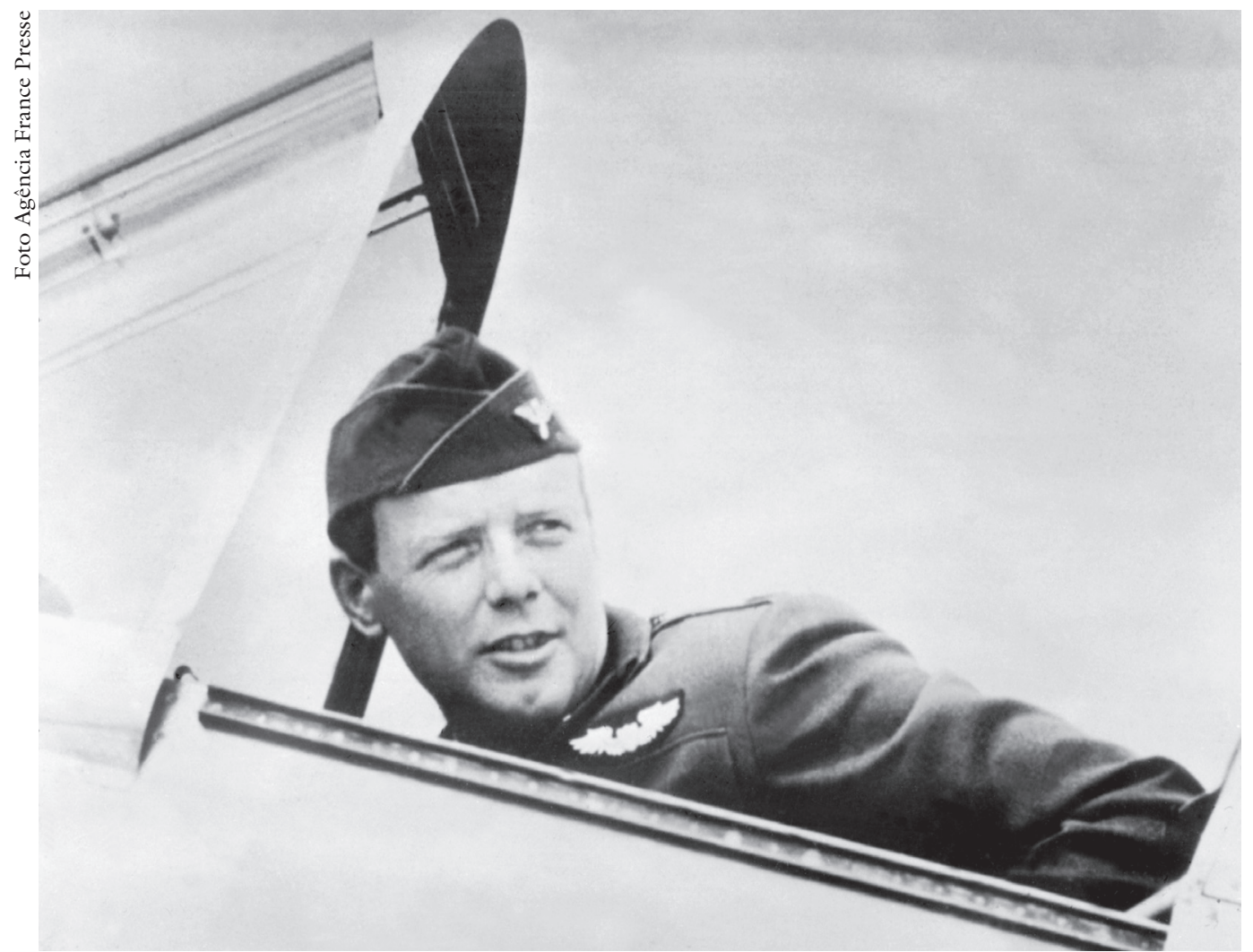

Em 21 de maio de 1927, o piloto Charles A. Lindbergh (foto) pousou seu aeroplano Espírito de St. Louis perto de Paris, completando o primeiro vôo solo sobre o Oceano Atlântico.

\section{Um novo público}

$\mathrm{Na}$ Alemanha, o teatro engajado tinha como único respaldo o forte movimento operário. A partir de 1928, a esquerda obtém uma expressiva votação e o Partido Comunista Alemão passou a apoiar com entusiasmo a movimentação teatral que vinha se desenvolvendo durante toda a década de 1920.

A transferência de Brecht para Berlim, em 1924, coincide com o movimento ascensional do teatro político. Brecht trabalha com Piscator e, graças a ele, convence-se da necessidade de fazer um teatro político. As influências de Piscator e, também, da vanguarda russa fizeram-no refletir sobre a necessidade de revolucionar a forma do teatro, reflexão que o acompanhou pelo resto da vida.

O encontro da intenção política com o espírito vanguardista manifesta-se inicialmente nas chamadas peças didáticas. Essas peças não foram escritas para serem encenadas; consistiam basicamente em exercícios para os atores. $O$ vôo sobre o oceano - peça didática radiofônica para rapazes e moças é, talvez, a mais interessante delas. Brecht encena a façanha de Lindbergh que, pela primeira vez na história da humanidade, cruzou o oceano num avião. A peça apresenta uma utilização inédita do rádio: foi feita para o rádio e o rádio é "personagem" da peça, pois é ele que narra a epopéia do herói. 
$\mathrm{Na}$ época, Paul Claudel, que havia passado muitos anos no Japão, encenou uma peça influenciada pelo teatro Nô. A peça, chamada Cristovão Colombo, retrata a descoberta do Novo Mundo em nome da religião. Brecht, aproveitando a idéia, retratou a "redescoberta do Velho Mundo em nome da nova tecnologia" (Willet, 1967, p.146).

Como os construtivistas russos, Brecht expressava o seu entusiasmo com o progresso técnico. O socialismo era a própria promessa do progresso social, avanço das forças produtivas rebelando-se contra as relações de produção. $\mathrm{O}$ teatro, nesse momento, é invadido pela técnica: esteiras rolantes, palco giratório, introdução de filmes etc. Nos textos teóricos do período, Brecht usa constantemente termos como montagem, processo, máquina, instrumento, experimento, ciência, produção etc.

O ativismo cultural do período deve-se à formação de um novo público, produtor e consumidor de arte, que exige a renovação do fazer artístico. Quando se fala da arte na República de Weimar, a atenção volta-se exclusivamente para as expressões da "alta cultura", o expressionismo e a nova objetividade, e tende-se a ignorar o movimento cultural subterrâneo que se desenvolveu em torno do movimento operário. ${ }^{3}$

Em primeiro lugar, vale lembrar a existência da imprensa operária que serviu de referência para as novas práticas teatrais. Alguns dados são esclarecedores. Uma das publicações, o Jornal Ilustrado do Trabalhador, chegou a ter uma tiragem de 350 mil exemplares. ${ }^{4}$ Esse e outros jornais tinham uma orientação totalmente diferente da imprensa burguesa e que não se restringia apenas à posição política. Havia um empenho em fazer que o leitor operário se identificasse com o jornal. Procurava-se, para isso, "transmitir a idéia de coletividade, de pertencer a um conjunto maior, portanto, de quebra de isolamento e do anonimato, características dos meios de comunicação burgueses e da 'imprensa operária tradicional"” (Marcondes, 1982, p.33). Um das formas era o envolvimento do leitor e sua participação direta por meio de artigos e cartas, gerando amplo material a ser aproveitado pelo teatro político.

A participação do público ocorreu também por meio da federação dos corais operários ligados à social-democracia. A federação dos corais reunia mais de quatorze mil conjuntos vocais, totalizando 560 mil participantes, em sua maioria operários. ${ }^{5}$

O grande meio de comunicação de massa do período era o cinema, que atraía milhões de pessoas fascinadas pela nova arte às salas de projeção que proliferaram em toda a Alemanha. Em 1924, dois milhões de entradas foram vendidas, para sessões que tinham início de manhã e se estendiam até de madrugada (Richard, 1992, p.226-30).

Em 1925, os comunistas alemães fundam a firma Prometheus, para a criação e divulgação de filmes. Analisando a filmografia partidária, uma estudiosa observou: 
A contraposição entre a cultura burguesa decadente, sentimental e individualista, e a cultura proletária, rica de sentimentos viris, expressões da força, da combatividade e da solidariedade do movimento operário, se estende ao cinema. À "dramaturgia da ficção", oferecida pelo cinema oficial, tenta-se opor uma “dramaturgia da realidade", que coloca em evidência a capacidade documentária do novo meio... (Ascarelli, 1981, p.86)

Priorizando o aspecto documental do cinema e sua utilidade política, não se levava em conta a especificidade da linguagem cinematográfica. Coube aos pensadores de vanguarda, como B. Balász e Brecht, fazerem as primeiras teorizações sobre as possibilidades revolucionárias da linguagem cinematográfica. Em 1932, Brecht, Eiler, Ottwalt e Dudow produziram o filme Kuble Wampe em que exploraram as possibilidades técnicas do novo meio. No mesmo período, Walter Benjamin escreve sobre as possibilidades abertas pelo rádio (Benjamin, 1987). ${ }^{6}$

Os filmes políticos, entretanto, ficaram restritos aos documentários russos e à produção local centrada nas reportagens sobre a condição operária. A tentativa de criar um cinema alternativo ao oficial para conquistar a audiência popular fracassou com o advento do cinema falado, que encareceu o custo da produção a tal ponto de torná-lo inviável para os partidos de esquerda e sindicatos. Em 1930, a firma Prometheus fecha suas portas.

A disputa para conquistar os corações e mentes teve no rádio um campo de batalha com características originais.

Em sua origem, o rádio surgiu como um substituto do telégrafo, sendo, por isso, conhecido inicialmente como "sem-fio". Esse aparelho rudimentar era usado nos navios para transmissões telegráficas em código. Em 1916, houve uma revolta pela independência da Irlanda e os revoltosos, de forma pioneira, usam o "sem-fio" para transmitir mensagens. Essa foi a primeira utilização que se conhece do rádio moderno. Marshall McLuhan (1979, p. 342 - grifo nosso), comentando o episódio, observou:

Até então, o sem-fio fora utilizado pelos barcos como "telégrafo" mar-terra. Os rebeldes irlandeses utilizaram o sem-fio de um barco, não para uma mensagem em código, mas para uma emissão radiofônica, na esperança de que algum barco captasse e retransmitisse a sua estória à imprensa americana. E foi o que se deu. A radiofonia já existia há vários anos, sem que despertasse qualquer interesse comercial.

O rádio nasce, assim, para permitir a interação entre os homens e não para ser o que depois veio a se tornar - uma aparelho de emissão controlado pelos monopólios e a serviço de sua lógica mercantil.

Os estudos sobre a história do rádio na Alemanha mostram, a propósito, que esse meio de comunicação teve a sua origem também ligada a uma rebelião - a revolução operária de 1918-1919. ${ }^{7}$

À semelhança da Revolução Russa, o movimento operário alemão organizou-se em soviets. Durante essa breve experiência revolucionária, o rádio faz sua 


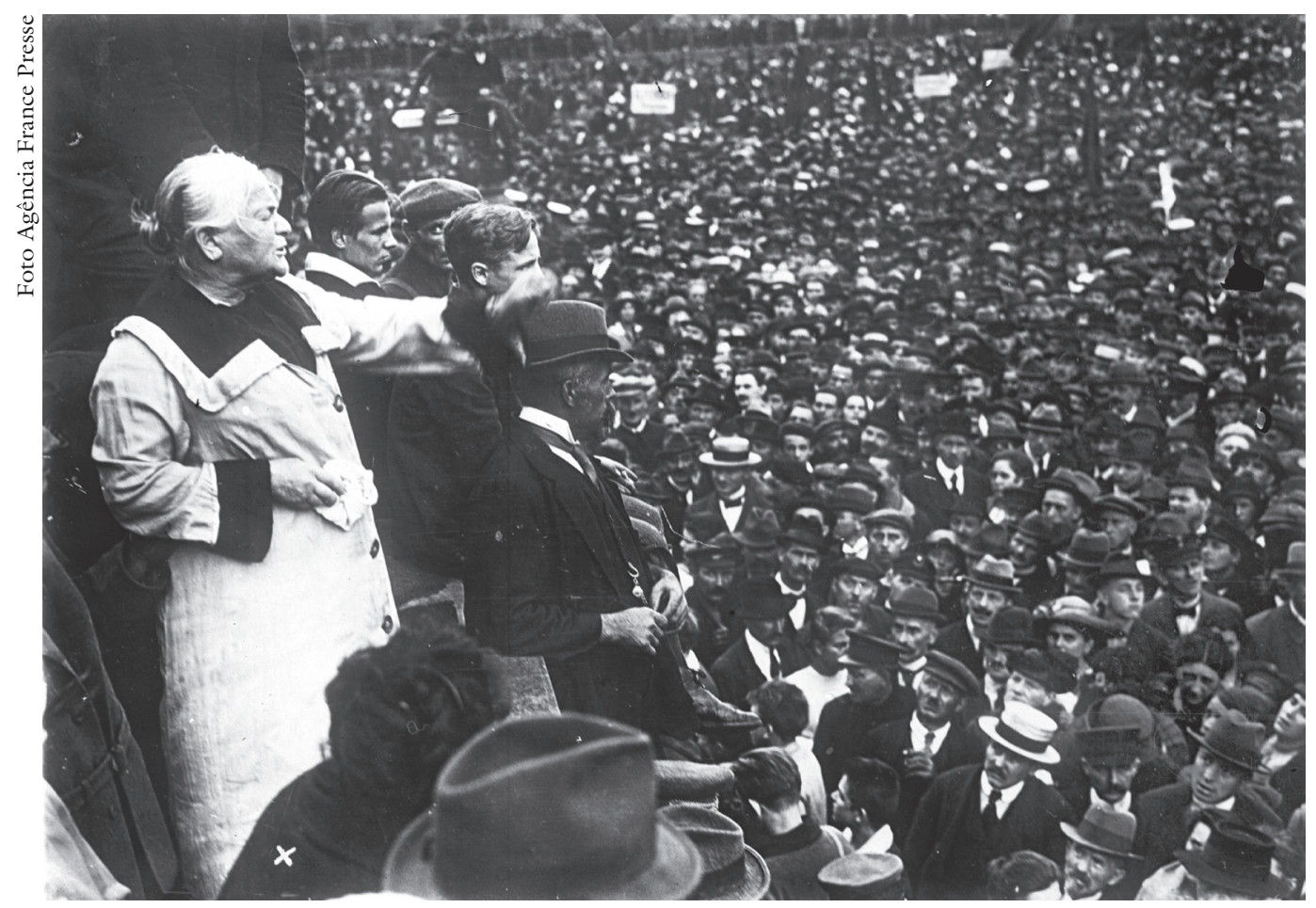

A deputada comunista alemã Clara Zetkin discursa para trabalhadores na década de 1930.

estréia, servindo como meio para coordenar o movimento nas várias regiões do país e manter contato com o regime revolucionário da Rússia. O rádio surge, pois, como um instrumento de mobilização política, e, só depois de cinco anos, com a revolução derrotada, é que se estabeleceu a "radiodifusão pública da diversão", ou seja, passou a ter uma função comercial e a monopolizar o "comércio acústico", segundo a feliz expressão de Brecht.

Ao lado das emissoras comerciais, contudo, proliferam as rádios ligadas ao movimento operário. Inicialmente, os trabalhadores fazem aparelhos de emissão em larga escala, com o objetivo de divulgar informações políticas e concorrer com as emissoras oficiais que permaneciam distantes da vida da classe trabalhadora. Paralelamente, criaram-se as "comunidades de ouvintes": instalavam-se amplificadores nas ruas para ouvir e debater as notícias veiculadas.

Esses grupos que construíam rádios reúnem-se em abril de 1924 na ArbeiterRadio-Klub Deutschland. Segundo informes da polícia, a associação agrupa, em 1924, quatro mil sócios, e em 1926, de oitocentos a 1.500 (Dahal, 1981, p.29).

É nesse contexto que Brecht intervém com sua "Teoria do rádio", respaldado pela existência do movimento das rádios operárias que, entretanto, a cada dia vai conhecendo a presença sufocante da censura. Quando o tempo fecha de vez, os ativistas passam a interceptar as emissoras oficiais para fazer discursos políticos.

Com a repressão crescente, os grupos econômicos monopolizaram finalmente esse meio de comunicação, apossaram-se da transmissão e transformaram o público em mero receptor. E isso, afirma Brecht, não ocorreu por razões 


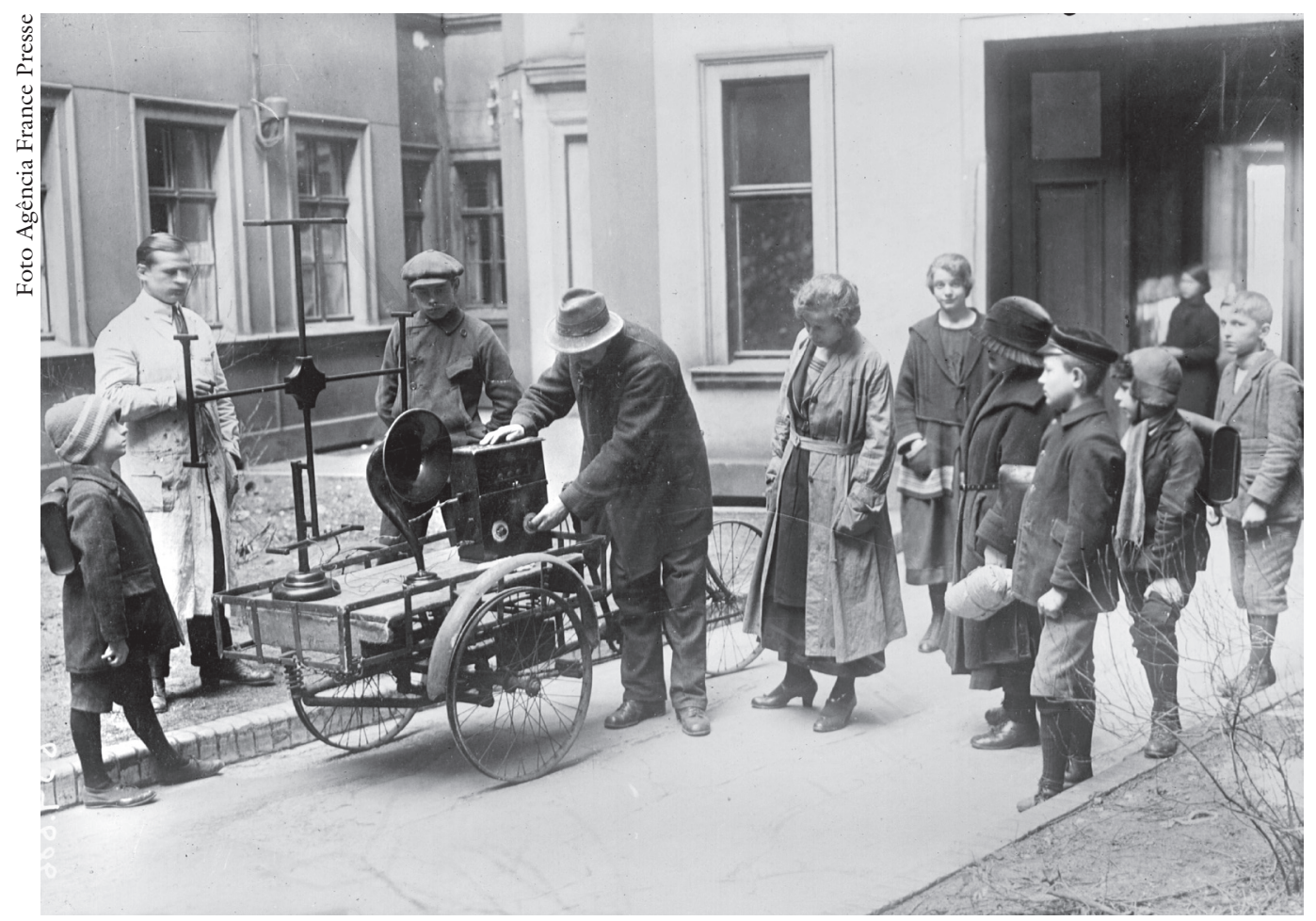

Audição de um aparelho de rádio montado sobre triciclo na Alemanha, na década de 1920.

técnicas: uma simples modificação pode transformar qualquer aparelho de rádio num instrumento que, ao mesmo tempo, recebe e transmite mensagens. Mas as possibilidades da técnica, ou melhor, o desenvolvimento das forças produtivas encontrava-se bloqueado pelas relações de produção e sua expressão jurídica - as relações de propriedade. Brecht reivindica a transformação desse aparelho de distribuição num verdadeiro instrumento de comunicação.

O monopólio dos meios de comunicação, por um lado, e a existência de um outro tipo de público produtor e consumidor, por outro, delimitam o espaço em que Brecht se debate. Pode-se, então, entender o paradoxo brechtiano: a luta contra o monopólio da fala coexistindo com "a tentativa inédita de utilização dos recursos do rádio". Comentando O vôo sobre o oceano, Brecht (1992b, p.184) observa que a peça "não deve servir-se da radiodifusão atual, mas que deve modificá-la. A concentração de meios mecânicos, assim como a especialização crescente na educação [...] requerem uma espécie de rebelião por parte do ouvinte, sua ativação e reabilitação como produtor". E acrescenta: "Esta não é certamente a maneira mais importante de utilização do rádio, mas sem dúvida se insere em toda uma série de experiências que caminham nesse sentido".

\section{Um texto profético}

Os escritos de Brecht sobre o rádio não mereceram ainda a devida atenção. São poucos os estudos dedicados àquela intervenção feita no calor da hora e com uma antevisão que ainda hoje surpreende. ${ }^{8}$ 
A argumentação brechtiana é bastante simples: a comunicação é um processo interativo e o rádio, como um substituto do telégrafo, foi feito para permitir a interação entre os homens. Mas não foi isso que aconteceu: os grupos econômicos monopolizaram esse meio de comunicação, apossaram-se da transmissão e, desse modo, transformaram todos em meros receptores, e o rádio tornou-se um mero aparelho de emissão.

E isso não ocorreu por razões técnicas: uma simples modificação transforma qualquer aparelho de rádio num instrumento que, ao mesmo tempo, recebe e transmite mensagens. De repente, o rádio sofre uma brutal limitação em sua capacidade. O invento revolucionário, ao ser apoderado e monopolizado pelos grupos econômicos, transforma-se rapidamente numa velharia, "um descobrimento antediluviano". A atrofia do rádio é, assim, mais um capítulo da história da contradição entre o desenvolvimento das forças produtivas e as relações de produção.

Já naquela época, Brecht critica os apologistas do rádio que costumavam valorizar tudo o que contivesse "possibilidades" sem se preocupar nunca com os "resultados". O rádio, diz Brecht, tinha "a possibilidade de dizer tudo a todos, mas, pensando bem, não havia nada a ser dito". O rádio comercial não nasceu porque era necessário: "não era o público que aguardava o rádio, senão o rádio que aguardava o público". Um vez inventado, o rádio saiu atrás do público. Onde está o público? Há um público para o jornal, outro para o esporte, outro para a música etc. O que fez o rádio? Foi atrás do público "alheio". Passou a transmitir notícias para atrair os leitores de jornal; esporte, para concorrer com os estádios esportivos; música, para laçar os freqüentadores das salas de concerto; peças teatrais, para atingir os amantes do teatro etc.

Assim, o rádio não criou nada de novo, apenas reproduziu os procedimentos próprios dos meios anteriores. Cada novo meio de comunicação parece condenado a representar o papel de vampiro que se alimenta das invenções anteriores. ${ }^{9}$

Brecht, escrevendo no início da radiodifusão foi profético: o que ele diz sobre o rádio vale também para a televisão e a internet. A televisão, também, ao surgir, vampirizou os antigos meios de comunicação. Basta lembrar aqui sua relação vampiresca com o cinema e com o teatro. A mesma coisa nos dias de hoje vem ocorrendo com a internet e promete se repetir com a televisão digital. A internet, além de vampirizar os meios de comunicação anteriores, segue os seus passos: $\mathrm{o}$ que foi inventado para ser um novo instrumento de comunicação para os usuários está se desvirtuando. Esses cada vez mais são meros receptores e consumidores. Receptores de propaganda comercial de produtos que podem ser comprados sem precisar sair de casa. E consumidores "ativos" que trabalham de graça para o capital toda vez que utilizam o computador para fazer transações bancárias.

Essas novas formas de desvirtuamento dos meios de comunicação, contudo, expressam também a nova etapa da contradição entre o desenvolvimento das forças produtivas e as relações de produção (e sua expressão jurídica: a pro- 
priedade privada). Uma vez mais, as possibilidades atrofiadas dos novos meios de comunicação e seus pífios resultados chamam a atenção para o caráter arcaico das relações de propriedade. A antiga queixa do direito de propriedade autoral do livro, solapado pelas fotocopiadoras, tornou-se rapidamente superada pelos recursos da internet, que, a cada novo dia, fazem aflorar a irracionalidade das relações de produção bloqueando o progresso social e o nascimento de um novo mundo.

Brecht não queria apenas "democratizar" o acesso dos consumidores à radiodifusão, mas "abalar a base social deste aparato". Não queria também contribuir com inovações, mas impulsionar as inovações "à sua missão básica".

Com a derrocada do movimento revolucionário, colocou-se, na Alemanha, a questão do controle do rádio. Quem deve controlar o rádio? A Telefunken e a Lorenz, duas gigantes da indústria de radiodifusão, além de fabricarem os aparelhos, queriam ter o monopólio da emissão. O Estado, porém, logo percebeu a importância estratégica do rádio e quis mantê-lo sob o seu exclusivo controle. Depois de muita discussão, chegou-se a um acordo: o Estado mantém o controle, mas fornece concessões para os grupos interessados. O movimento operário alemão, apesar de afastado do poder, também pleiteou uma concessão, pois, afinal, ele já tinha uma experiência de radiodifusão. $\mathrm{O}$ Estado, evidentemente, não concedeu e o rádio passou a ser um instrumento político diretamente voltado contra o movimento operário e a serviço da ascensão do nazismo.

Quando Brecht amargou o exílio, o rádio o acompanhou, mas sua função era bem diferente de suas possibilidades emancipatórias:

- Você, pequena caixa que trouxe comigo

Cuidando para que suas válvulas não quebrassem

Ao correr do barco ao trem, do trem ao abrigo

Para ouvir o que meus inimigos falassem

Junto ao meu leito, para minha dor atroz

No fim da noite, de manhã bem cedo

Lembrando as suas vitórias e o meu medo:

Prometa jamais perder a voz! (Brecht, 2000, p.272)

\section{Notas}

I São cinco os artigos que compõem a "Teoria do rádio": o mais importante deles é "O rádio como aparato de comunicação", publicado neste número de ESTUDOS AVANÇADOS em cuidadosa tradução de Tercio Redondo, revista por Marcus Vinicius Mazzari. Os demais textos são: "O rádio: um descubrimento antediluviano?", "Sugestões aos diretores artísticos do rádio", "Aplicações" e "Comentário sobre O vôo sobre o oceano" (cf. Brecht, 1984), edição preparada por Werner Hecht. O último texto, extraído do caderno I dos Versuche, foi traduzido para o português por Fernando Peixoto em Brecht (1992a, p.184). 
2 Uma extensa documentação sobre o teatro operário encontra-se reunida nos quatro volumes da obra Le théâtre d'agit-prop de 1917 a 1932 (Lausanne: La Cité - L'age d'homme, 1978). Os dois primeiros tratam da presença desse movimento teatral na Rússia e os demais na Alemanha, França, Polônia e nos Estados Unidos. Agradeço a indicação bibliográfica e a generosidade de Claudia Arruda Campos e Iná Camargo Costa. Ver também, Storch (2004).

3 Um dos exemplos dessa omissão é o livro de Peter Gay (1978).

4 Cf. o importante estudo de Ciro Marcondes (1982, p.35).

5 Cf. E. Schumacher, Die dramatischen Versuche Bertolt Brechts 1918-1933 (Berlin: Rüten und Loening, 1955) (apud Koudela, 1991, p.50).

6 Tempos depois, Adorno, em seu exílio nos Estados Unidos, foi convidado por Paul Lazarsfeld para participar de uma pesquisa sobre a audição de música no rádio. Escreve, então, para Benjamin perguntando sobre os modelos de audição que ele havia desenvolvido na Alemanha no início dos anos 1930 (cf. Müller-Doohm, 2003, p.370). O autor esclarece que esses modelos de audição foram desenvolvidos em analogia com o teatro épico de Brecht: "seu objetivo era didático e queria combater a mentalidade de consumo frente ao novo meio de comunicação".

7 Ver, a propósito, Marcondes (1982), Ascarelli (1981) e Dahal (1981).

8 Uma honrosa exceção é Hans-Magnus Enzensberger (1978). Ver, também, o interessante trabalho do jornalista Leão Serva (1997), que retoma as idéias de Brecht para pensar temas contemporâneos.

9 O jornalista Leão Serva (1997, p.23-4), um dos primeiros a divulgar a "Teoria do rádio" de Brecht entre nós, escreveu um belo livro em que comenta esse processo de vampirização: “O jornal publicava trechos de livros e decretos. Os primeiros fotógrafos reproduziam os retratos em óleo. O cinema mostrava pequenas cenas da vida cotidiana e de mercados, de circo etc. O rádio emite concertos, para ocupar espaço das sinfônicas, e notícias, para ocupar os espaços dos jornais. A TV chega fazendo tudo o que o rádio e o cinema faziam, também jornalismo, concertos etc. Repete-se sempre a mesma rotina: meios novos ‘fagocitam' os procedimentos anteriores simplesmente para ter seu público. Ao mesmo tempo, esta cópia parece banalizante ao que cede os procedimentos e precede no tempo".

Referências bibliográficas

ASCARELLI, R. Comunicazioni di massa e movimento operaio. In: Critica marxista, Roma, n.1, Riunite, 1981.

BENJAMIN, W. Deux formes de vulgarisation. In: Trois pièces radiophoniques. Paris: Chiristian Bourgois Éditeur, 1987.

BRECHT, B. Teatro dialético. Rio de Janeiro: Civilização Brasileira, 1967. . El compromisso en literatura y arte. 2.ed. Barcelona: Península, 1984. . Teatro completo 3. 2.ed. Rio de Janeiro: Paz e Terra, 1992a.

. O vôo sobre o oceano. In: . Teatro completo. 2.ed. Rio de Janeiro: Paz e Terra, 1992b. v.3. 
BRECHT, B. Ao pequeno aparelho de rádio. In: . Poemas. 1913-1956. Trad. Paulo

César de Souza. São Paulo: Editora 34, 2000.

DAHAL, P. Detrás de tu aparato de radio está el enemigo de clase (Movimiento de radios obreras en la República de Weimar). In: BASSETES, L. (Org.) De las ondas rojas a las radios libres. Barcelona: Editorial Gustavo Gili S.A., 1981.

ENZENSBERGER, H.-M. Elementos para uma teoria dos meios de comunicação. Rio de Janeiro: Tempo Brasileiro, 1978.

GAY, P. A cultura de Weimar. Rio de Janeiro: Paz e Terra, 1978.

KOUDELA, I. D. Brecht: um jogo de aprendizagem. São Paulo: Edusp, Perspectiva, 1991.

MARCONDES, C. O discurso sufocado. São Paulo: Loyola, 1982.

McLUHAN, M. Os meios de comunicação como extensão do homem. São Paulo: Cultrix, 1979.

MÜLLER-DOOHM, S. En terra de nadie. Theodor Adorno, una biografia intelectual. Barcelona: Herder, 2003.

RICHARD, L. Uma distração de massa: o cinema. In: A República de Weimar. São Paulo: Cia. das Letras, 1992. p.226-30.

SERVA, L. Babel. A mídia antes do dilúvio e nos últimos tempos. São Paulo: Mandarim, 1997.

STORCH, W. O teatro político na República de Weimar. In: CARVALHO, S. de. (Org.) O teatro e a cidade. São Paulo: Prefeitura do Município de São Paulo, 2004.

WILLET, J. O teatro de Brecht. Rio de Janeiro: Zahar, 1967.

Celso Frederico é professor da Escola de Comunicações e Artes da USP e bolsista do CNPq. @-celsof@usp.br

Texto recebido em 12.1.2007 e aceito em 26.1.2007. 